
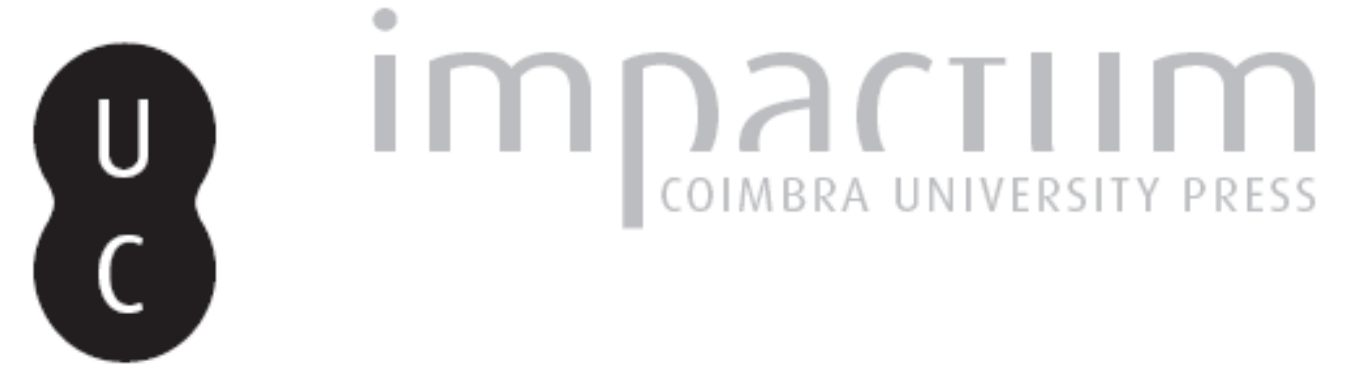

\title{
Media digitais: o milagre da multiplicação dos géneros
}

\author{
Autor(es): $\quad$ Santos, Clara Almeida; Peixinho, Ana Teresa
}

Publicado por: Imprensa da Universidade de Coimbra

URL persistente:

URI:http://hdl.handle.net/10316.2/43069

DOI:

DOI:http://dx.doi.org/10.14195/0870-4112_3-3_1

Accessed : $\quad$ 26-Apr-2023 14:04:41

A navegação consulta e descarregamento dos títulos inseridos nas Bibliotecas Digitais UC Digitalis, UC Pombalina e UC Impactum, pressupõem a aceitação plena e sem reservas dos Termos e Condições de Uso destas Bibliotecas Digitais, disponíveis em https://digitalis.uc.pt/pt-pt/termos.

Conforme exposto nos referidos Termos e Condições de Uso, o descarregamento de títulos de acesso restrito requer uma licença válida de autorização devendo o utilizador aceder ao(s) documento(s) a partir de um endereço de IP da instituição detentora da supramencionada licença.

Ao utilizador é apenas permitido o descarregamento para uso pessoal, pelo que o emprego do(s) título(s) descarregado(s) para outro fim, designadamente comercial, carece de autorização do respetivo autor ou editor da obra.

Na medida em que todas as obras da UC Digitalis se encontram protegidas pelo Código do Direito de Autor e Direitos Conexos e demais legislação aplicável, toda a cópia, parcial ou total, deste documento, nos casos em que é legalmente admitida, deverá conter ou fazer-se acompanhar por este aviso.

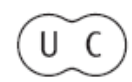




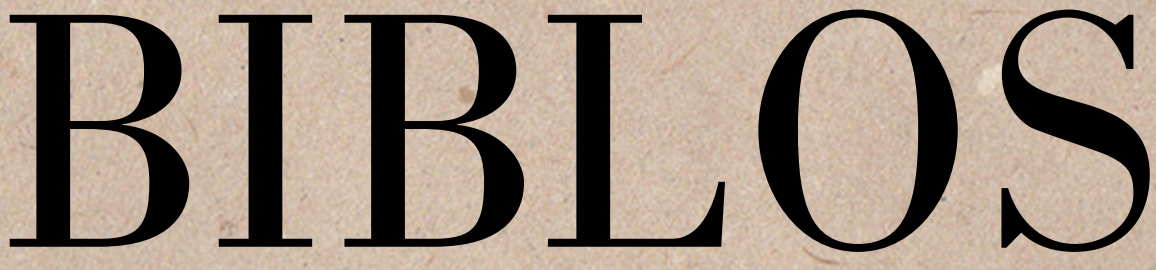

Revista da Faculdade de Letras da Universidade de Coimbra

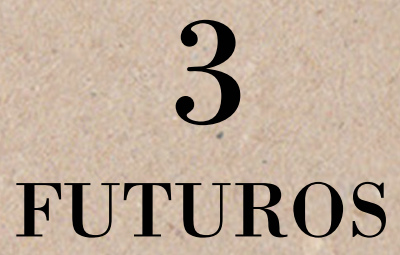

NÚMERO 3, 2017

3. ' SÉRIE 


\title{
MEDIA DIGITAIS: \\ O MILAGRE DA MULTIPLICAÇÃO DOS GÉNEROS
}

\author{
Digital media:
}

The miracle of the multiplication of genres

\author{
CLARA ALMEIDA SANTOS \\ clara.santos@fl.uc.pt \\ Faculdade de Letras da Universidade de Coimbra / CEIS20
}

ANA TERESA PEIXINHO

apeixinho71@gmail.com

Faculdade de Letras da Universidade de Coimbra / CEIS20

DOI

https://doi.org/10.14195/0870-4112_3-3_1

Recebido em setembro de 2016

Aprovado em dezembro de 2016

Biblos. Número 3, 2017 • 3.a Série

pp. 11-32 


\title{
CLARA ALMEIDA SANTOS E ANA TERESA PEIXINHO
}

\section{RESUMO.}

Pretende-se, neste artigo, problematizar os géneros jornalísticos no meio digital. Uma leitura atenta do novo ecossistema mediático possibilita que se repense a questão dos géneros desta formação discursiva à luz de processos de reciclagem e de hibridizaçáo.

Assim, partindo da discussão teórica desencadeada, na segunda metade do século XX, na qual os estudos de Martinez Albertos assumiram um papel seminal, e tendo como referência a produçấo textual do primeiro medium português assumidamente digital - o Observador - procura-se compreender em que medida as transformaçôes nas rotinas de produção e na disseminação de produtos mediáticos, aceleradas na era digital, implicam também mudanças ao nível dos géneros jornalísticos. Reconhecendo-se que raramente os géneros foram categorias fechadas ou modelos puros, hoje, especialmente, o jornalismo contemporâneo náo se compagina com definiçóes estanques, sendo antes meio de cultura para os fenómenos de hibridização já referidos, que tornam qualquer tipologia rapidamente obsoleta. Arrisca-se, assim, focar a atençấo em dois fenómenos que conhecem grande vigor no momento atual do estado da arte: as newsletters e os explicadores.

Palavras-chave: Géneros jornalísticos; Media digitais; Newsletters; Explicadores; Hibridização.

\begin{abstract}
.
The aim of this article is to rethink journalistic genres in a digital context. A thorough observation of the contemporary media ecosystem enables us to look at discourse genres as a result of processes of hybridization and recycling. Our starting point is the theoretical discussion provided by Martinez Albertos' studies (in the 2 nd half of the 20th century) and the textual production of the first reference Portuguese medium that is entirely (and exclusively) online - Observador. We try to understand how changes in journalistic production and dissemination routines, accelerated by the digital shift, are responsible for changes as far as journalistic genres are concerned. Considering that these genres were rarely considered as hermetic categories or pure models, contemporary journalism practices provide the perfect setting for hybridization, rendering all typologies obsolete.

We focus on two of these phenomena, that we consider particularly relevant as far as state-of-the-art journalism is concerned: newsletters and explainers.
\end{abstract}

Keywords: Journalistic genres; Digital media; Newsletters; Explainers; Hybridization. 
A 8 de junho de 2014, um artigo publicado na revista The Economist refletia sobre a "moda dos artigos "explicadores", afirmando que estes "estão aqui para ficar". Começando por criar um momento de sarcasmo à volta dos "explicadores", aludindo a uma eventual necessidade futura de criar "explicadores dos explicadores dos explicadores", o autor (identificado apenas com as iniciais L. S., como é norma na publicação ${ }^{1}$ ) discorre acerca da presença cada vez mais frequente dos explicadores enquanto género jornalístico. Os explicadores são afirmados como “forma jornalística” e prova-se que a sua existência percorreu já algum caminho, citando Jay Rosen que, já em 2008, afirmava a importância deste tipo de textos no jornalismo. O notável professor de jornalismo e pensador dos media propóe, inclusivamente, que a explicação preceda a informação, numa total inversão da estrutura habitual dos conteúdos noticiosos (Rosen 2014). Rosen publica, em dezembro de 2014, uma lista com as 21 tendências que estáo a mudar o jornalismo. Em 17. ${ }^{\circ}$ lugar surge a referência ao "futuro do jornalismo de contexto e de explicador". Para o autor, trata-se de uma resposta do jornalismo a um certo tipo de procura, no sentido económico do termo. Os explicadores seriam, então, uma das estratégias jornalísticas que fornecem o contexto necessário para entender as novas notícias. $\mathrm{O}$ ambiente digital, caracterizado pelo excesso de informação disponível, é o meio de cultura perfeito para soluções que ajudem a criar sentidos. Também Matt Thompson (2009) vê nos explicadores (independentemente da forma que possam tomar) um antídoto para a sobrecarga informativa presente na web.

A partir da assunção do papel cada vez mais importante de tipos textuais jornalísticos novos, como os "explicadores", pretende-se, com o presente artigo, criar um momento de reflexão sobre os géneros jornalísticos na era digital,

1 O jornal The Economist, fundado em 1843, mantém a rotina do anonimato dos seus redatores. Esta tradição foi encetada como um meio de fazer parecer que poucos eram muitos. Hoje em dia, a prática é justificada com o princípio de fazer com que os autores falem a uma voz coletiva: os temas são discutidos colegialmente e frequentemente as matérias são escritas a várias mãos. Só as reportagens especiais (na edição semanal impressa) constituem uma exceção a esta regra, a par dos mais raros editoriais escritos pelos editores que se aposentam. Curiosamente, e a propósito da necessidade de explicar e de se explicar, esta informação consta de um artigo publicado no The Economist, na rubrica "The Economist explains - Explaining the world, daily". 
tendo por base a constatação de que o ecossistema mediático contemporâneo exige que repensemos as tipologias clássicas.

\section{OS GÉNEROS COMO GRELHAS DE LEITURA E DE PRODUÇÃO}

A reflexão sobre genologia ${ }^{2}$ jornalística tem sido feita desde o momento em que os géneros jornalísticos emergiram como entidades mais ou menos estáveis, num contexto de autonomização e profissionalização da atividade. A criação de uma superestrutura definida para as notícias - a célebre pirâmide invertida - e a necessidade de distinção entre opinião e informação são dois aspetos importantes que contribuem, como é sabido, para a definição de um quadro genológico no âmbito da textualidade jornalística. De facto, tendo em consideração a matriz clássica do jornalismo, que se encontra em manuais de técnicas de redação e em livros de estilo, parece muito claro que, desde a autonomizaçáo do jornalismo como campo profissional e discursivo, a textualidade a ele inerente se dividia em dois grandes modos fundacionais ${ }^{3}$ : a narrativa e a argumentação - precisamente aquelas que Teun van Dijk considera serem as duas principais superestruturas textuais $^{4}$ (Van Dijk 1998) - que correspondiam essencialmente à consagrada fronteira entre informação e opinião, cunhada pelo Daily Courant ainda no século XVIII, porém, só mais tardiamente adotada no jornalismo continental.

A problematização dos géneros no jornalismo exige, porém, uma clarificação de dois campos de atuação diversos: por um lado, o reconhecimento de que a

\footnotetext{
2 Termo sugerido por Paul van Tieghem e retomado na Teoria da Literatura de R. Welleck e A. Warren na década de 60 do século XX (Welleck e Warren 1962: 293). Como se perceberá pela discussão desenvolvida, a reflexão sobre géneros do discurso jornalístico não pode separar-se da reflexão que, neste âmbito, foi desencadeada pela Teoria da Literatura e pelos estudos de pragmática linguística.

3 Conceito utilizado na discussão sobre géneros literários, que se refere a "categorias abstratas, transhistóricas [...] encerrando virtualidades não exclusivamente literárias" (Reis 1995: 238).

4 Para Teun van Dijk, existem duas grandes superestruturas textuais, através das quais utilizamos textualmente a linguagem: a narrativa e a argumentativa. A superestrutura é, segundo Van Dijk, "um tipo de esquema abstrato que estabelece a ordem global de um texto e que se compóe de uma série de categorias cujas possibilidades de combinação se baseiam em regras convencionais" (1998: 144).
} 
praxis profissional tem da questão, que poderá ser observada na leitura de livros de estilo ${ }^{5}$, de manuais de técnicas de redação e, mais concretamente, na prática textual empírica ${ }^{6}$; por outro lado, a abordagem teórica à questão dos géneros, que surge no âmbito dos Estudos de Jornalismo, em meados do século XX, e que se desenvolverá de modo mais circunstanciado abaixo. É também interessante uma incursão pelo território do ensino do Jornalismo, correlato com a dimensão profissional, merecendo especial atenção a presença da genologia jornalística nos curricula académicos. Como afirma Rodríguez Betancourt (2004: 323), "estudiar los géneros, su origen y evolución, sus procedimientos, su tipología y sus perspectivas significa estudiar el Periodismo que se hace en los medios". Seria, entâo, de supor que o estudo dos géneros jornalísticos e da Teoria dos Géneros ocupasse um lugar de relevo no ensino do Jornalismo no ensino superior, pressuposto contrariado por uma breve análise comparada de planos de estudo de quatro instituiçóes de ensino superior de referência?. Uma leitura desses curricula leva-nos a concluir que os géneros jornalísticos não estão no topo das prioridades

5 A consulta aos livros de estilo de dois órgãos de comunicação social portugueses de referência - jornal Público e Agência Lusa - não deixam margens para dúvidas. O Livro de estilo do jornal Público tem uma secção intitulada "Critérios, Géneros e Técnicas", na qual se começa por definir: "Tal como náo existe objetividade em estado puro, não existem nos textos jornalísticos fronteiras absolutas entre informação, interpretação e opiniāo. De qualquer modo, há três níveis essenciais na construção das peças: a apresentaçáo dos factos, que podem ser a divulgação da opiniáo de terceiros — a informaçáo; o relacionamento desses factos entre si — a interpretação; e o juízo de valor sobre esses factos — a opiniáo" (Público 2005: 46). Quer isto dizer, não explicitando nunca a questâo dos géneros, baseia-se a tipologia textual em critérios de objetividade / subjetividade discursiva. O Livro de estilo da Lusa, sem a sistematicidade classificatória, explica como escrever notícias, sínteses, flashes, entrevistas, perfis e reportagens (Lusa 2012).

6 Segundo Paulo Nunes da Silva, "apenas o texto constitui um objeto empírico, porque só ele é uma entidade fisicamente manifestada, seja através da oralidade ou da escrita", embora seja com base na realidade concreta da prática textual que se definem os tipos e géneros discursivos (Silva 2012: 82).

7 Ensaiámos uma pesquisa exploratória nos curricula de Jornalismo e Ciências da Comunicação em quatro instituiçōes de ensino superior, duas no Brasil - Universidade Federal do Rio de Janeiro e Universidade de São Paulo - e em Portugal - Universidade Nova de Lisboa e Universidade do Porto. Entendemos que as instituições seriam comparáveis, uma vez que são todas universidades públicas, situadas nas maiores cidades de cada um dos países e conhecidas por serem estabelecimentos de ensino superior de referência. 
de ensino dos cursos de jornalismo (ou congéneres) das universidades de referência no Brasil e em Portugal $^{8}$, muito possivelmente porque a longevidade dos curricula académicos não se compadeça com as mudanças sucessivas a que estes géneros estão sujeitos, enquanto entidades socio-discursivas que acompanham as alterações da formação discursiva a que pertencem.

Naturalmente que entre a prática textual e discursiva quotidiana e a teoria, que visa definir, clarificar e categorizar, existe um hiato epistemológico e temporal considerável, pesem embora as relações de mútua implicação. Além do mais, como realçam alguns autores, de uma perspetiva teórica, os géneros notabilizam-se quer pela sua elevada capacidade de reprodução, quer pela facilidade com que "entram e saem de cena" (Giltrow; Stein 2009: 10).

\footnotetext{
$8 \mathrm{Na}$ Universidade Federal do Rio de Janeiro, a Graduação em Comunicação Social - Jornalismo não apresenta nenhuma unidade curricular cujo nome se relacione diretamente com os géneros jornalísticos. O mais aproximado, em termos de conteúdos, pode ser encontrado na unidade curricular "Redação Jornalística I", onde se lecionam "princípios teóricos, técnicos e históricos da redação jornalística para meios impressos, eletrônicos e digitais. Relaçấo entre o texto e o processo de produção jornalístico. Estrutura da notícia. Hierarquização e angulação de notícias". Já na unidade curricular "Redação Jornalística II" podemos encontrar a continuação da matéria, sendo elencados os seguintes temas: "Produçấo de textos para meios impressos, eletrônicos e digitais. Interpretação em textos noticiosos. Textos jornalísticos não noticiosos; Copidesque. Normas e critérios editoriais para os textos. Manuais de redaçâo". Na Universidade de S. Paulo, e a partir da análise da estrutura do curso de Comunicaçáo Social - Habilitaçấo em Jornalismo, os géneros jornalísticos surgem apenas como um ponto no programa de "Fundamentos do Jornalismo", uma disciplina optativa livre. "Géneros jornalísticos e estrutura" é uma alínea do tema "Estrutura do texto". Já em Portugal, na Universidade Nova de Lisboa, encontramos no percurso de Jornalismo, uma das opçôes do perfil do $1^{\circ}$ Ciclo em Ciências da Comunicaçáo, a unidade curricular "Géneros Jornalísticos", uma das nove opçôes condicionadas oferecidas aos alunos. A Universidade do Porto, na Licenciatura em Ciências da Comunicação: Jornalismo, Assessoria, Multimédia, propốe "Tipologias de imprensa" como um dos tópicos do ponto Introdução da unidade curricular "Técnicas de Expressão Jornalística I - Imprensa". Na unidade curricular de "Técnicas de Expressão Jornalística II - Imprensa”, o tema é abordado novamente, centrando-se em três géneros jornalísticos: a entrevista, a crónica e o artigo. São entendidos como género pois os pontos do programa, para cada um destes tipos textuais, propóem-se abordar o "enquadramento do género". Será interessante referir ainda que não foi encontrada qualquer referência a géneros jornalísticos online ou relacionados com ciberjornalismo na unidade curricular de "Técnicas de Expressão Jornalística I - Online”. Em “Técnicas de Expressão Jornalística II - Online”, no ponto referente à "Prática do Ciberjornalismo", referem-se os seguintes conteúdos: Normas e estilos ciberjornalísticos; Narrativa hipertextual; Multitextualidade e Produção para diferentes suportes.
} 
No caso da reflexão sobre géneros jornalísticos, a questão é ainda mais problemática, sobretudo porque existem classificaçôes diversas em função da cultura jornalística e do enfoque teórico; e existem categorias genológicas dissemelhantes, até em função dos autores e das suas matrizes teóricas. Contemplando a teorização desencadeada em Espanha, na segunda metade do século XX, desde os estudos seminais de Martinez Albertos da década de 70, encontram-se diversas categorizaçóes e opinióes, por vezes, díspares.

Parece, pois, importante, para a clarificação da questão, e sem a pretensão de construir um estado da arte sistemático sobre o tema, ter em consideraçáo três pressupostos essenciais: i) o de que a questão dos géneros no jornalismo está em parte dependente do conceito de género utilizado quer em linguística, quer em teoria da literatura, áreas fundacionais da reflexão teórica sobre o tema; ii) o de que é importante clarificar bem a terminologia utilizada, uma vez que a discussão sobre géneros aparece, recorrentemente, inquinada pela adoção de critérios classificatórios e de conceitos de natureza diversificada; iii) o de que se trata de uma reflexão que deve ser fundada sempre na evolução e dinâmica do próprio jornalismo, evitando ver o género como uma mera "postulação normativa ou autoritária, com puro propósito classificativo” (Reis 1995: 235)”.

Assim, entender a constituição e funcionamento dos géneros jornalísticos pressupóe que se recupere o legado de $\mathrm{Bakhtin}^{10}$ e a sua definição de géneros de discurso. Contrariando a herança saussureana, que entendia o uso da língua como atividade eminentemente individual, o autor russo defendeu que a atividade dos falantes - concretizada pela produção de textos vários - é um ato de

9 Esta advertência é feita por Carlos Reis no campo da genologia literária. Porém, acredita-se poder adaptá-la à formaçáo discursiva do jornalismo.

${ }^{10}$ Segundo Lia Seixas, em trabalho que aborda precisamente a evolução dos géneros jornalísticos, Bakhtin foi o responsável pela adaptação da teoria genológica a práticas discursivas fora do âmbito da literatura: "Seu conceito de dialogismo, ao colocar o berço dos gêneros na esfera prosaica da linguagem, seduziu todos aqueles que queriam trabalhar com o discurso cotidiano, precisavam compreender a esfera do reconhecimento, ou ainda, analisar o hibridismo e a pluralidade. Os mais diversos gêneros da comunicação cotidiana, além da comunicação cultural organizada, ganham o estatuto de gêneros da linguagem, tipos que merecem ser analisados" (Seixas 2009: 41). 
criatividade individual sempre enquadrada, contudo, por modelos socialmente partilhados, decorrendo no quadro de géneros de discurso dependentes da condição social da linguagem em uso. Para o autor, qualquer enunciado verbal é sempre uma combinação das formas da língua cuja adaptação aos contextos e situaçóes é social:

[...] tout énoncé particulier est assurément individuel, mais chaque sphère d'usage du langage élabore ses types relativement stables d'énoncés, et c'est ce que nous appelons les genres discursifs. (Bakhtin 1984: 265).

Idêntica abordagem adotou Marie-Laure Ryan, defendendo que os géneros condicionam o uso da língua em dois domínios diferentes: numa perspetiva puramente linguística, o género condiciona as escolhas semânticas, sintáticas e fonológicas; num segundo nível, os géneros, dada a sua dependência cultural, constituem-se como conjuntos de procedimentos e orientaçóes que permitem uma maior eficiência na comunicação textual (Ryan 1979: 334). Dominique Maingueneau, já no final da década de 90 do século passado, também advoga que os géneros discursivos são construçóes essenciais aos diversos tipos de discurso, resultando da "crescente cristalização dos textos que constantemente se adaptam às necessidades específicas da formaçáo sociodiscursiva em que cada género teve origem", conforme explica Paulo Nunes da Silva, na excelente síntese que escreve sobre a questão (Silva 2012: 66).

Nesta linha de raciocínio, entender-se-á o jornalismo como um tipo de discurso, conceito contíguo ao de formação discursiva de Foucault ${ }^{11}$, cuja prática textual se processa mediante um conjunto de géneros, mais ou menos estável, responsável pela construção de grelhas de produção textual, com capacidade modalizadora de horizontes de expectativas.

\footnotetext{
${ }^{11} \mathrm{Na}$ linha de Foucault, dir-se-á que qualquer ato discursivo deriva de sistemas enunciativos próprios fundamentados em fatores de natureza sociocultural e psicológica a que dá o nome de formaçōes discursivas (Foucault 1969: 152-154).
} 
Reconhece-se, assim, como válida a definição proposta por Paulo Nunes da Silva: "um género discursivo náo constitui um texto ou um conjunto de textos, mas um conceito que corresponde a uma classe de textos abstraída, neste caso, a partir de diversos critérios" (Silva 2012: 81). No âmbito do discurso jornalístico, aceita-se que a notícia, a reportagem, o editorial, a entrevista, o perfil, etc. sejam géneros discursivos diferenciados, que resultam de propriedades típicas dos textos que os constituem, sendo que é importante ter em atenção as hipóteses de cruzamento e hibridizaçáo potenciadas pela porosidade de fronteiras entre eles.

O intuito classificatório que preside ao conceito de género depende, em grande medida, de parâmetros de natureza diversificada: além de propriedades de natureza estilística, consideram-se também questóes de estrutura textual e de conteúdo, de periodicidade e dimensáo, bem como a variedade de efeitos perlocutórios ${ }^{12}$ pretendidos. Ora, tendo em consideração o conceito de género e a forma como ele se constituiu, a sua historicidade e diacronia, pode concluir-se que, à semelhança do que sucede com os géneros literários ${ }^{13}$, também no jornalismo eles evoluem, se transformam e váo-se sucedendo num processo de renovaçáo, dependente dos contextos, dos dispositivos de mediação e da relação comunicacional estabelecida.

Parece, portanto, legítimo questionar hoje o aparecimento de novos géneros jornalísticos, decorrentes das múltiplas transformaçóes culturais, tecnológicas e comunicacionais que o advento da web trouxe ao ecossistema mediático. Se a história dos media e do jornalismo nos tem mostrado que géneros como a notícia ou a crónica tiveram na sua origem motivaçóes histórico-culturais, profundamente enraizadas nas evoluções tecnológicas e sociais, parece legítimo reconhecer que a grande revolução hipertextual que vivemos há quase duas décadas tem suscitado novas práticas de produção textual dentro do jornalismo.

\footnotetext{
${ }^{12}$ Sobre esta queståo, veja-se Silva 2012: 65-75.

${ }^{13}$ Carlos Reis esclarece a este respeito: “[...] os géneros literários são por natureza instáveis e transitórios, sujeitos como se encontram ao devir da História, da Cultura e dos valores que as penetram e vivificam [...]" (Reis 1995: 247).
} 


\section{CRISE E OPORTUNIDADE NA TEORIA DOS GÉNEROS JORNALÍSTICOS}

As transformações nas rotinas de produção e na disseminação de produtos mediáticos, aceleradas na era digital, implicam também mudanças ao nível dos géneros jornalísticos. As taxonomias, nesta como em outras áreas, são sistemas complexos e necessariamente abertos à mudança, como atrás se disse. Mais, a crise da teoria dos géneros jornalísticos já foi anunciada e analisada por vários autores (Díaz Nocci, Salaverría 2003). Reconhecendo-se que raramente os géneros foram categorias fechadas ou modelos puros, hoje, especialmente, o jornalismo contemporâneo não se compagina com definiçóes estanques, sendo antes meio de cultura para os fenómenos de hibridizaçáo já referidos, que tornam qualquer tipologia rapidamente obsoleta. E, no entanto, como diz Juan Cantavella, estamos permanentemente à procura de "formas novas, originais e mais produtivas para comunicarmos com os leitores" (Cantavella 1999: 64).

O domínio absoluto da narrativa hipertextual, essencialmente construída numa lógica intertextual e multimedial, veio, na última década, transformar a nossa relação com a realidade. Recorrendo aos prenúncios de Guy Debord, sobre a civilização do espetáculo, Marc Lits reflete sobre a transformação radical dos suportes tecnológicos e dos nossos quadros de referência que implicam necessariamente uma recomposição dos modos de organização narrativa e dos papéis dos agentes no sistema mediático. Num recente artigo, o autor explica circunstanciadamente essa evolução, propondo, inclusive, a criação de uma hipernarratologia capaz de responder às mudanças da narrativa em ambiente digital com um novo aparato teorético (Lits 2015: 13-27).

Podemos afirmar, com Giltrow e Stein (2009), que a existência de "pré-sinais" confirma o pacto que dá conta da presença de géneros. Usando o exemplo dos jornais, o leitor é conduzido a saber - através de fórmulas visuais ou textuais, geralmente enunciadas no espaço paratextual - que está na presença de artigos de opinião, por exemplo. Ou, como defende Echeverría (1998: 10): "los géneros forman parte de ese segundo lenguaje, no verbal, que envuelve a las palabras y trasmite al lector datos relevantes sobre lo que está leyendo". Pode dizer-se 
que, neste sentido, os géneros são arquitextos ${ }^{14}$, fundamentais para conformar as práticas de produção textual e, sobretudo, a receção / leitura.

Porém, a existência de géneros jornalísticos específicos pode ir além da sua materialidade textual. Pode ser, como afirmam Salaverría e Cores (2009), a prova de vida de uma nova forma de jornalismo: "la aparición de nuevos géneros periodísticos vendrá a probar que ha nacido una nueva forma de periodismo" (Salaverría, Cores 2009: 183). À semelhança do que sucede na literatura, também o aparecimento de géneros novos confirma a vitalidade das linguagens e dos campos discursivos, correspondendo à evolução de práticas específicas. Sabe-se, pois a história dos media o explicou já, como o aparecimento de um género como a notícia, no século XIX, anunciou um novo período na história da imprensa que, da fase romântica e panfletária, paulatinamente se firma como indústria; ou como a evolução do romance-folhetim oitocentista, publicado no rodapé da página dos jornais, para a radionovela foi fruto de uma evolução tecnológica, coincidente com o aparecimento de um novo medium, que, por sua vez, implicou uma alteração dos hábitos culturais.

Como explicam Janet Giltrow e Dieter Stein, a questão dos géneros ganhou nova força precisamente com o advento da Internet, precisamente porque esta fez aparecer géneros novos ou suscitou a reciclagem de géneros antigos (Giltrow; Stein 2009: 1-2)

$\mathrm{Na}$ verdade, a história da constituição de um género como a notícia é bastante eloquente quanto à influência de critérios externos, de natureza extralinguística, na sua génese e cristalização. Como diversos autores têm explicado, a notícia e as propriedades que a definem, nomeadamente a estrutura de pirâmide invertida, foram resultado de um processo histórico que contou essencialmente com a evolução tecnológica - o aparecimento do telégrafo, a Guerra da Secessão, o aparecimento dos primeiros enviados:

Os progressos tecnológicos foram um dos fatores principais na modificação da estrutura da notícia. Nos começos da imprensa escrita não existia

\footnotetext{
${ }^{14}$ Usa-se o conceito de arquitexto de Genette (1987).
} 
o atual conceito de informação [...] Em 1840, com o aparecimento do telégrafo, a estrutura das notícias sofre a primeira modificação profunda. (Fontcuberta 1999: 58)

A notícia parece ser o único género que escapa à divergência doutrinária em relação à classificação dos géneros jornalísticos em função da primeira grande distinção entre informação e opiniāo (Salaverría; Cores 2009) sendo, sem dúvida, um género informativo, diríamos mesmo o género informativo por excelência:

La noticia es el género emblemático del periodismo. Lo ha sido antes de internet y lo sigue siendo también en la Red. Los cibermedios ofrecen un lugar preeminente a este género, que puebla la mayor parte de su espacio editorial. (Salaverría; Cores 2009: 151)

Não obstante, o advento da era digital, nomeadamente o aparecimento da web 2.0, trouxe consigo mudanças no modo de pensar este género. É conhecida a teoria de João Canavilhas, segundo a qual a tradicional superestrutura da pirâmide invertida deu gradualmente lugar a uma outra, cujo critério de ordenação textual passou a ser a quantidade e não a relevância: referimo-nos à pirâmide deitada, nova forma de produzir e consumir notícias na web (Canavilhas 2006, 2010).

Não nos interessa, no tempo e espaço deste artigo, em que o digital (em todas as suas manifestaçóes) ocupa uma parte substancial do terreno jornalístico, olhar para a evolução da notícia enquanto estrutura, na sua transmutação do impresso para o digital. As características essenciais do género mantêm-se, no sentido em que uma notícia continua a ser o género jornalístico informativo por excelência, consistindo num relato sumário de um acontecimento. Responde, fundamentalmente e a partir de um nó principal (a que tipicamente se chama lead), às questóes: quem fez o quê, onde e quando. As dimensôes de multimedialidade, hipertextualidade e interatividade introduzidas (ou desenvolvidas sem precedentes) pelo jornalismo digital não alteram esta definição, podendo, no entanto, criar outros níveis de complexidade e de estruturação textual, como foi já aludido anteriormente. 
Salaverría e Cores (2009) já propuseram uma taxonomia para classificar os géneros ciberjornalísticos, partindo do estudo de caso dos meios de comunicação digitais em Espanha. Além da notícia, os autores identificam outros géneros, dentro dos quadrantes informativo, interpretativo, dialógico e argumentativo. Importa, neste momento, realçar que a grande parte dos contributos teóricos para a discussão dos géneros jornalísticos tem chegado, precisamente, de Espanha, tendo sido a Universidade de Navarra, aliás, pioneira nesta questão (Seixas 2009) ${ }^{15}$.

Utilizamos, pois, a classificação proposta pelos autores já referidos por ser, dentro do quadro dos autores mais profícuos nesta matéria, uma das que primeiro se debruça de forma mais circunstanciada sobre os géneros especificamente ciberjornalísticos, tecendo pontes sobre a diferente natureza dos meios, para se centrar mais na permeabilidade dos géneros às características próprias do digital. Antes, porém, deve sublinhar-se, com Giltrow e Stein, as duas principais características dos géneros discursivos na internet, pois elas afetam também os géneros do ciberjornalismo de que aqui se fala: a sua abertura pragmática e a sua enorme fluidez (Giltrow, Stein 2009: 9).

Assim, dentro dos géneros informativos, encontramos a infografia como o género que, tendo uma génese no jornalismo impresso (e, acrescentamos nós, televisivo), mais se terá desenvolvido dentro do quadro digital, alegando os autores mesmo a existência de um relevante salto qualitativo. Assim, as possibilidades trazidas sobretudo pela multimedialidade e pela hipertextualidade permitem a integração de vários elementos e a complexificação das estruturas textuais. Discute-se, ainda assim, se a infografia multimédia (expressão que os autores preferem a infografia digital) se pode considerar como um género independente.

Seguindo a mesma classificação, encontramos depois os dados em bruto, que se consubstanciariam em dados pouco ou nada contextualizados, passíveis de ser utilizados isoladamente ou como complementos de outros géneros eminentemente factuais.

\footnotetext{
${ }^{15}$ Uma completa resenha das várias propostas de classificação de géneros jornalísticos e ciberjornalísticos é apresentada por Lia Seixas (2009).
} 
Já dentro dos géneros ditos interpretativos, sugere-se a inclusão da reportagem e da crónica. Não nos deteremos neste último como tendo características especificamente ciberjornalísticas, uma vez que Salaverría e Cores escrevem num tempo (2009) em que os blogs tinham um protagonismo na internet que hoje se pode considerar muito atenuado. No entanto, a crónica de opinião tem, nos jornais digitais, um espaço muito considerável, mantendo este género, genericamente, as especificidades que o jornalismo tradicional lhe confere. Relativamente à reportagem, ela surge efetivamente como multimédia e reconhecida de tal maneira que há registo de Prémios Pullitzer de Jornalismo atribuídos a este género ciberjornalístico. Aliás, a última das perguntas frequentemente colocada no site destes que são os mais prestigiados prémios de jornalismo é: "How do multimedia elements fit into "writing" categories, such as Feature Writing and Editorial Writing?" Sendo a respetiva resposta: "While juries will place primary emphasis on the quality of the writing, multimedia elements are welcome in order to enhance an entry"16.

Verificamos, entre os mais recentes premiados, a existência de reportagens verdadeiramente multimédia, explorando as diferentes possibilidades oferecidas pela utilização de recursos digitais ${ }^{17}$. Podemos considerar como reportagem multimédia aquela que é, desde a sua origem, concebida para o ambiente digital, que articula, na sua construçáo, vários formatos, enfatizando as possibilidades da hipertextualidade, da multimedialidade e da interatividade. Uma reportagem verdadeiramente multimédia não poderia ser transmutada sem perdas para a tradicional estrutura exclusivamente textual ou audiovisual.

São ainda enumerados por Salaverría e Cores os géneros designados como dialógicos, nos quais se encontram a entrevista, o forum, o chat e o questionário, e os géneros argumentativos como o editorial, a coluna, as cartas ao diretor, as críticas ou resenhas, e ainda o cartoon ou vinheta.

\footnotetext{
${ }^{16} \mathrm{http}: / /$ www.pulitzer.org/page/frequently-asked-questions. Acedido a 30/7/2016.

17 Ver, por exemplo, http://www.tampabay.com/projects/2015/investigations/florida-mental-health-hospitals/cuts. Acedido a 30/7/2016.
} 
Relativamente à entrevista e às suas especificidades no enquadramento digital, poder-se-á dizer que esta abre novas possibilidades de inscrição de diferentes graus de interatividade. Exemplo disso são as perguntas dirigidas pelo público ao entrevistado ou as perguntas e respostas feitas em tempo real. $\mathrm{O}$ chat acaba por ser a concretização desta simultaneidade, numa versão em que não há "hierarquia" entre participantes (embora possa existir um moderador ou facilitador) nem um limite, à partida, ao número de pessoas envolvidas. No entanto, tanto o chat como o forum (que não é específico dos meios digitais, uma vez que versôes deste género se podem encontrar nos meios radiofónico e televisivo) não nos parecem ser construçôes textuais jornalísticas, uma vez que a polifonia é constituída sobretudo por vozes que não pertencem a jornalistas e que, normalmente, não sustentam opiniôes estruturadas como género.

Falta ainda mencionar, seguindo a proposta de Salaverría e Cores, os géneros que se abrigam no quadrante argumentativo, praticamente identificados como géneros de opinião. Seriam eles, então, o editorial, a coluna, o "suelto"18 (opinião breve, normalmente anónima ou escrita sob pseudónimo), as cartas ao diretor, a crítica ou resenha e a vinheta ou cartoon. Não nos deteremos muito sobre estes géneros, uma vez que são, em geral, "los que menos han ahondado y aprovechado las posibilidades comunicativas de la red" (Salaverría; Cores 2009: 177). Manifestando-se em textos tipicamente de tipo autoral, apesar de veiculados em meios digitais, mantêm as características plasmadas nos legacy media. A transmutação para o digital poderá fazer com que estes géneros, tornando-se mais ciberjornalísticos, passem simultaneamente a integrar-se melhor nos géneros dialógicos.

Como a maioria dos autores reconhece, a hibridização e a dificuldade em estabelecer fronteiras são realidades insuperáveis. E, no entanto, a tentativa de analisar este tema, nas suas manifestaçóes concretas e na sua permanente mutabilidade, permite-nos compreender melhor o que é o ciberjornalismo hoje, nas suas motivaçôes, práticas e consumos.

\footnotetext{
${ }^{18}$ Não encontramos, em português, tradução para este género, tendo-se optado por manter a designação original, em espanhol.
} 


\section{NEWSLETTERS E EXPLICADORES}

Interessa, portanto, e neste momento, sublinhar a existência de novas formas de construçấo de narrativas que surgem pela natureza do próprio ambiente digital e das novas exigências que são sua consequência e, simultaneamente, fonte de novos fenómenos. Depois de um surto significativo de estudos sobre os géneros ciberjornalísticos, o interesse parece ter esmorecido nos últimos anos. Talvez as mudanças na internet, sobretudo a passagem para a web social e para a web semântica, e nos produtos mediáticos disponíveis online assim o tenham ditado. Construir teorias e taxonomias exige uma certa estabilidade dos conceitos e, no domínio em causa, a única estabilidade garantida reside na constância da mudança.

Arrisca-se, ainda assim, focar a atenção em dois fenómenos que conhecem grande vigor no momento atual do estado da arte. Comece-se pelas newsletters. O modo epistolar não é novidade no campo jornalístico, já que, como explica Ross Eaman, trata-se de:

One of the earliest forms of news dissemination. Their development was facilitated by the growth of private and state postal networks in the $16^{\text {th }}$ century. They continued to play an important role even after the introduction of corantos and in fact constituted one of their main sources of information. (Eaman 2009: 217)

Embora se reconheçam os argumentos que defendem ser a epistolaridade um modo discursivo e não um género textual, poder-se-á dizer que, no caso da sua utilização jornalística, terá toda a pertinência enquadrá-la como género dialógico. Entendemos que esta assunção faz ainda mais sentido no caso das newsletters que circulam através do protocolo de email e que podem ser subscritas digitalmente. Acontece que estas newsletters são, na sua generalidade, agregadores de notícias com assinatura. Segmentadas por temas ou por enfoque (em funçáo da hora de envio, por exemplo), representam as escolhas de alguém, nomeadamente opçóes de editores, diretores ou subeditores, jornalistas reconhecidos. A questáo da legitimidade é, neste caso, crucial, uma vez que o sucesso do género (que pode ser medido com rigor em funçáo do número de subscritores e da taxa de abertura 
das newsletters) depende da identificação dos públicos com as escolhas que são feitas. Trata-se de uma espécie de gatekeeping transmutado pelo digital. Thorson e Wells (2015) propóem que se olhe para os principais aportes da teoria do gatekeeping, considerando o paradigma comunicacional atual, numa abordagem a que chamam de curated flows, que poderíamos traduzir livremente por "curadoria de fluxos". Esta proposta parte de dois pressupostos:

(1) that contemporary networked publics are subject to a multiplicity of information curators, increasingly on an individual, rather than mass, basis; and (2) that processes of curation may be better conceptualized as drawing information in rather than keeping it out.

(Thorson; Wells 2015: 27)

Como género dialógico que se defende ser (e que considera o destinatário como um indivíduo que, ademais, escolheu subscrever aquele produto específico), a newsletter coloca questôes relacionadas com a interatividade que devem ser equacionadas a dois níveis distintos: ao nível do medium, cujas potencialidades técnicas o habilitam a ser mais ou menos interativo; e ao nível textual, pois o próprio discurso deve ele mesmo ser intrinsecamente interativo ${ }^{19}$. Se a escrita tradicional da carta deixou de integrar os hábitos quotidianos do século XXI, é muito interessante perceber como, num contexto digital, há a necessidade de recuperar certas propriedades do epistolar que foram progressivamente caindo em desuso no quotidiano das trocas interpessoais. Destas características salientamos essencialmente três: a coloquialidade discursiva; o hibridismo genológico e a subjetividade.

A entrada das newsletters nos media digitais em Portugal deu-se com o Observador, jornal exclusivamente online que começou a ser publicado em maio de 2014. Vários órgãos de comunicação, como o Expresso, o Diário Económico, entre outros, investiram, depois, neste que se advoga ser um género ciberjornalístico, se nấo novo, pelo menos reciclado.

19 Sobre a tipologia da interatividade como propriedade hipertextual, veja-se Ryan 2001: 204-224. 
No que diz respeito aos explicadores, com que se iniciou este artigo, tendo já sido explanado o seu conteúdo, pode afirmar-se que este género é facilmente enquadrável no quadrante informativo dos géneros ciberjornalísticos. Mas poderia também encaixar-se na dimensão interpretativa, uma vez que a contextualização que opera exige já um grau de intervenção bastante sofisticado por parte do jornalista que o produz. Tentando definir o perfil de questóes a que responde o explicador, usando o modelo clássico aplicado às notícias (que devem apresentar solução para as perguntas Quem? Fez o quê? Onde? Quando? Como? Porquê?), será útil, desde logo, perceber quem explica. Neste género, como nas newsletters, a questáo da autoria é fundamental. Ainda que possa não se vislumbrar o autor individual da explicação, como acontece e já foi referido no caso de The Economist, só prestaremos atenção à explicação se reconhecermos credibilidade e autoridade a quem explica. A segunda questâo diz respeito ao conteúdo, ou seja, ao que explica, tipicamente enunciado no título do explicador. Coloca-se, depois, a questão de como é explicado, sendo possível uma grande diversidade de linguagens e formatos, do texto ao vídeo, passando por infografias (e cruzando-se assim, hipoteticamente, com outros géneros ciberjornalísticos, afirmando a cultura de hibridização).

Qualquer que seja o formato em causa, os explicadores não são geralmente muito longos. Trata-se, afinal, de um género ciberjornalístico que apresenta uma adaptação total ao ecossistema mediático sustentado em redes, sobretudo em redes sociais, parecendo ter inscrito na sua matriz a partilha.

\section{CONCLUSÃO}

Seguindo a pauta da evolução do ciberjornalismo ou jornalismo online proposta por vários autores, como Fidler (1997) ou Cabrera-González (2000), e que mostram o desenvolvimento dos media jornalísticos digitais, percorrendo um caminho que passa pelos modelos assentes na repetição, enriquecimento, renovação e inovaçấo, pode dizer-se que géneros ciberjornalísticos como as newsletters ou os explicadores, mesmo recuperando fórmulas que há muito o jornalismo já conhece, correspondem à fase da inovaçâo ou modelo multimédia. São géneros pensados em função de um modelo de negócio que já existe e está em franca 
expansão, sendo orientados para os anúncios e próprios de uma cultura mediática que é web first. Acrescente-se ainda que, ao contrário da notícia, da reportagem ou da entrevista, estes géneros ou não resistiriam a uma adaptação ao impresso e ao audiovisual ou sofreriam uma clara amputação das suas potencialidades.

Voltando a The Economist: a publicação escolheu, no final de 2015, os seus dez explicadores mais populares (em 2014 e 2013, já tinham sido selecionados os explicadores mais importantes: “top”). Olhar para os títulos destes explicadores ajuda a compreender a variedade de temas que interessaram ao público de The Economist, fornecendo também algumas pistas sobre a construção deste género ${ }^{20}$.

As mudanças operadas nos géneros jornalísticos podem ser a própria metáfora das mudanças operadas no jornalismo e na forma de contar histórias. Decretada a morte do jornalismo, transformado em conteúdos, e dos jornalistas, transformados em produtores de conteúdos, assistimos a uma verdadeira ressurreição digital de que os "novos" géneros são o santo sudário. As novas necessidades dos leitores-consumidores, as práticas de consumo, os suportes e as plataformas de distribuição parecem finalmente estar a encontrar eco no ambiente digital. $\mathrm{O}$ jornalismo online ou ciberjornalismo, abandonada a condição de parente pobre do jornalismo, descobre que um dos caminhos possível é fazer do género o medium. Até onde nos é dado ver no presente, será num contexto digital que se moverá o jornalismo do futuro. E este jornalismo do futuro deve ser analisado em termos projetivos e compreendido nas suas dinâmicas, numa perspetiva académica, mas também de promoção da literacia mediática por o futuro ser, parafraseando Woody Allen, “o sítio onde vamos passar o resto das nossas vidas". A começar já.

\footnotetext{
${ }^{20}$ Alguns dos títulos dos explicadores de The Economist: Por que tantos holandeses trabalham em tempo parcial? Por que as vendas da McDonald's estâo a baixar? Por que os suíços desindexaram o franco? Tudo o que quer saber sobre a queda de preços do petróleo. O que a Rússia está a tramar na Ucrânia. Tudo o que quer saber sobre o acordo nuclear iraniano. Por que o islão proíbe imagens de Maomé? Como funcionam os fundos de cobertura. O dress code para mulheres da Arábia Saudita. Por que o preço do ouro está a cair? (trad. nossa).
} 


\section{CLARA ALMEIDA SANTOS E ANA TERESA PEIXINHO}

\section{BIBLIOGRAFIA}

Bakhtine, Mikhaïl (1984). Esthétique de la création verbale. Trad. Alfreda Aucouturier. Paris: Gallimard.

Canavilhas, João (2006). "Webjornalismo: da pirâmide invertida à pirâmide deitada”, http://bocc. ubi.pt/pag/canavilhas-joao-webjornalismo-piramide-invertida.pdf (consultado a 30/7/2016).

Canavilhas, João (2010). "O novo ecossistema mediático" http://www.bocc.ubi.pt/pag/canavilhas-joao-o-novo-ecossistema-mediatico.pdf (consultado a 30/7/2016).

Díaz Noci, Javier; Salaverría, Ramón (2003) (coords.). Manual de redacción ciberperiodistica. Barcelona: Ariel Comunicación.

Díaz Noci, Javier (2004). “Teoría de los géneros ciberperiodísticos”. Comunicação apresentada ao II Congreso Iberoamericano de Periodiso Digital, em Santiago de Compostela, 29-30 de novembro de 2004, http://www.ufrgs.br/limc/participativo/pdf/generos.pdf (consultado a 30/7/2016).

Eaman, Ross (2009). Historical Dictionary of Journalism. Maryland / Toronto / Plymouth: The Scarecrow Press.

Echevarría Llombart, Begoña (1998). "Porqué hablar hoy de géneros periodísticos”, Comunicación y Estudios Universitarios, 8, 9-14 [Madrid: Fundación Universitaria San Pablo].

Foucault, Michel (1969). L'archéologie du savoir. Paris: Gallimard.

Genette, Gérard (1987). Introdução ao arquitexto. Trad. Cabral Martins. Lisboa: Vega.

Giltrow, Janet; Stein, Dieter (eds.) (2009). Genres in the Internet. Amesterdam, Filadelfia: John Benjamins.

Lits, Marc (2015). “As investigaçôes sobre a narrativa mediática e o futuro da imprensa”, Mediapolis, 1, 13-27 [Coimbra: Imprensa da Universidade de Coimbra].

LUSA (2012). Livro de estilo. Lisboa: Lusa.

Público (2005). Livro de estilo. 2. ${ }^{\mathrm{a}}$ ed. Lisboa: Público - Comunicaçáo Social S.A.

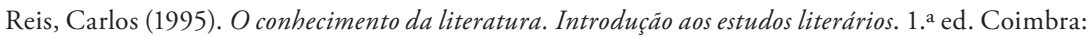
Almedina.

Rodríguez Betancourt, Miriam (2004). “Géneros periodísticos: para arropar su hibridez”, Estudios sobre el Mensaje Periodistico, 10, 319-328 [Madrid: Universidade Complutense de Madrid].

Rosen, Jay (2008). "National Explainer: A Job for Journalists on the Demand Side of News", http://archive.pressthink.org/2008/08/13/national_explain.html (consultado a 30/7/2016).

Rosen, Jay (2014). http://pressthink.org/2014/11/how-to-be-literate-in-whats-changing-journalism (consultado a 30/7/2016). 
Media digitais: o milagre da multiplicação dos géneros

Ryan, Marie-Laure (2001). Narrative as Virtual Reality. Immersion and Interactivity in Literature and Electronic Media. London: The Johns Hopkins University Press.

Salaverría, Ramón; Cores, Rafael (2009). "Géneros periodísticos en los cibermedios hispanos”, in Salaverría, Ramón (coord.). Cibermedios. El impacte de internet en los medios de comunicación en España. Sevilha / Zamora: Comunicación Social. Ediciones y publicaciones, 145-185.

Seixas, Lia (2009). Redefinindo os géneros jornalísticos. Proposta de novos critérios de classificação. Covilhã: Labcom.

Silva, Paulo Nunes da (2012). Tipologias textuais. Como classificar textos e sequências. Coimbra: Almedina.

Thompson, Matt (2009). "An antidote for web overload”, http://niemanreports.org/articles/an-antidote-for-web-overload (consultado a 30/7/2016).

Thorson, K.; Wells, C. (2015). "How gatekeeping still matters", in Vos, T.; Heinderyckx, F. (eds.). Gatekeeping in Transition. New York / London: Routledge, 25-44.

Van Dijk, Teun (1998). La ciencia del texto. Trad. Sibila Hunziger. 5.a ed. Barcelona: Paidós.

Wellek, René; Warren, Austin (1962). Teoria da literatura. Trad. José Palla e Carmo. Lisboa: Europa-América. 